\title{
Primary versus staged repair of Fallot with borderline pulmonary artery anatomy
}

\author{
Basem M. Abdelgawad ${ }^{1 *}$ (D, Mahmoud A. Elshafie ${ }^{1}$, Suzan Bayoumy ${ }^{2}$ and Elatafy E. Elatafy ${ }^{3}$
}

\begin{abstract}
Background: Surgical management of tetralogy of Fallot (TOF) can be either with a total primary repair or staged repair. The superiority of one technique over the other is still debatable, especially in developing countries with late presentation and limited resources. The objective of this study was to compare the outcome of patients with tetralogy of Fallot and borderline pulmonary anatomy defined as McGoon ratio between 1.2 and 1.6 who underwent primary versus staged repair.

Results: The patients were divided into two groups: group A included patients who underwent primary repair ( $n=120)$ and group $B$ included patients who underwent repair after previous modified Blalock-Taussig (MBT) shunt operation $(n=100)$. Patients in group $B$ were significantly older $(11 \pm 2.6$ vs. $7 \pm 3.1$ months; $p<0.001)$ and had higher McGoon ratio (1.61 \pm 0.07 vs. $1.5 \pm 0.08 ; p<0.001)$. In group $B$, the total operative time ( $277 \pm 21.3$ vs. $232 \pm 24.6 \mathrm{~min} ; p<0.001)$, cardiopulmonary bypass time ( $81 \pm 13.7$ vs. $60 \pm 11.2 \mathrm{~min} ; p<0.001)$, and ischemic time $(64 \pm 12$ vs. $53 \pm 7.1 \mathrm{~min} ; p<0.001)$ were significantly higher. There was no difference in postoperative complications between both groups. In-hospital mortality was nine patients (7.5\%) in group A and $6(6 \%)$ in group B $(p=0.791)$.

Conclusion: Primary repair of tetralogy of Fallot in patients with borderline McGoon ratio is safe with low morbidity and mortality. It has the potential of decreasing hospital stay, cost, and resource utilization of the two-stage repair.
\end{abstract}

Keywords: Tetralogy of Fallot, McGoon ratio, Primary Fallot repair, Blalock-Taussig shunt

\section{Background}

Tetralogy of Fallot (TOF) is the most frequent cyanotic heart disease with an incidence of 3-6 per 10,000 live births. Significant advances in the surgical repair of TOF have been achieved, with more than $90 \%$ of patients surviving to adulthood [1].

The optimum timing and options for surgical repair of TOF is still the subject of ongoing research. Different surgical strategies are available according to the underlying anatomy, and the surgical approach can be either a singlestage or a two-stage repair. The latter consists of initial palliation with a modified Blalock-Taussig (MBT), followed by total repair at a later stage [2]. Opinions diverge from those who prefer neonatal repair in all symptomatic TOF patients to those preferring to postpone

\footnotetext{
* Correspondence: bassem.abdelgawad@fmed.bu.edu.eg

${ }^{1}$ Cardiothoracic Surgery Department, Faculty of Medicine, Benha University,

15 Hasan Muwafi St., Hi Elrawdah," New Benha, Qalyobia 13518, Egypt
}

Full list of author information is available at the end of the article complete repair until later in life, depending on a temporary MBT shunt when necessary [3].

Two-stage repair avoids the risks of heart-lung machine in low-weight children. However, the early total correction has the benefits of avoiding MBT shunt complications, such as distortion of the pulmonary arteries, early relief of systemic hypoxia, which allows a normal rate of growth, preventing progressive right ventricle (RV) hypertrophy, and early normalization of cardiac chambers flow and pressure [4].

The objective of our study was to compare the outcomes of TOF patients with McGoon ratio between 1.2 and 1.6 who underwent primary repair versus those who underwent repair after a previous modified Blalock-Taussig (MBT) shunt.

\section{Methods}

Patients population

Our multicenter study included 220 consecutive TOF patients with McGoon ratio between 1.2 and 1.6 operated 
between January 2014 and June 2019. Patients were divided into two groups: group A included 120 patients who underwent primary repair and group B included 100 patients who underwent the two-stage repair. Patients were assigned to each group according to the preference of the surgical team. Patients who had an associated absent pulmonary valve, atrioventricular canal defect, or pulmonary atresia were excluded. The choice of the patients into either group was based on surgical team preference and experience.

\section{Preoperative parameters}

Patient data were retrospectively collected from the data registry in the cardiac surgery unit of each hospital. Preoperative data included patients' characteristics, echocardiographic, and multi-slice CT details, especially right ventricular outflow tract (RVOT) pressure gradient, degree of aortic overriding, size of the pulmonary annulus, and McGoon ratio.

\section{Surgical technique}

Median sternotomy was performed, whether primary or redo sternotomy. At the second stage, dissection of MBT shunt was done before cardiopulmonary bypass $(\mathrm{CPB})$ and then ligated and divided after starting bypass. Patent ductus arteriosus (PDA) was ligated and divided if present to free the pulmonary arteries. All operations were performed using aorto-bicaval cannulation with intermittent doses of cold blood cardioplegia for myocardial protection. The transatrial approach was chosen for ventricular septal defect (VSD) closure using Gore-Tex ${ }^{\oplus}$ or Dacron ${ }^{\circ}$ patch (Gore-Tex; W. L. Gore \& Associates, Inc., Flagstaff, Ariz). Trans-atrial infundibular resection was then performed and completed through a pulmonary arteriotomy "trans-atrial-transpulmonary approach.” Trans-ventricular resection was performed, especially when the trans-annular patch was indicated or with a narrow right ventricular outflow tract (RVOT), which was augmented by a pericardial patch. Pulmonary commissurotomy was performed in almost all patients, and when a small annulus was detected by not passing the calculated Hegar dilator size, our incision was extended few millimeters below the annulus. We have routinely augmented the main pulmonary artery using a pericardial patch. The patch was extended proximally across the annulus when indicated and distally to enlarge any existing branch pulmonary artery stenosis. The tricuspid valve was repaired if there was more than mild regurgitation with the saline test. After weaning from bypass, right ventricle and pulmonary artery (PA) pressures were directly measured, and pressure gradient less than 30 $\mathrm{mmHg}$ and $\mathrm{RV} / \mathrm{left}$ ventricle (LV) pressure less than $60 \%$ were accepted.

\section{Operative parameters}

Total operative, cardiopulmonary bypass, and crossclamp times, a gradient across RVOT, and RV/LV pressure after repair were collected.

\section{Postoperative parameters}

Duration of intensive care unit (ICU) stay, mechanical ventilation, and hospital stay, and complications including bleeding, arrhythmias, wound or chest infections, renal or hepatic dysfunction, and need of inotropic support were collected from medical charts.

Echocardiography was done before discharge to evaluate gradient across the RVOT, tricuspid insufficiency, pulmonary insufficiency, right and left ventricular functions, pericardial effusions, and any residual shunts.

\section{Statistical analysis}

Data interpretation and statistical analysis were performed using SPSS vs.25. (IBM, Armonk, New York, USA). Comparisons between the two groups were done using the independent $t$ test for numerical data. Categorical data were compared using the Chi-squared test. $p$ values less than 0.05 were considered significant.

\section{Results}

Two hundred and twenty TOF patients with McGoon ratio between 1.2 and 1.6 were divided into two groups according to the repair strategy.

\section{Preoperative and operative data}

Preoperative patients' data are presented in Table 1. There was a higher-pressure gradient across the RVOT in group B $(p=0.008)$. McGoon ratio was $1.4 \pm 0.12$ before shunt operation and was $1.61 \pm 0.07$ before the second stage in group B and was $1.5 \pm 0.08$ in group A.

Total operative, cardiopulmonary bypass, and ischemic times were higher in group B $(p<0.001)$. Postbypass evaluation of repair using RV/PA pressure and $\mathrm{RV} / \mathrm{LV}$ pressure was non-significant between the two groups $(33 \pm 6.3$ vs. $34 \pm 9$ in groups A and B respectively, $p=0.35$ ). All patients were weaned successfully from cardiopulmonary bypass with no intraoperative mortality (Table 2).

\section{Postoperative data}

Four patients, two in each group, were transferred to ICU with open-chest; three of them were exposed to longer bypass time with visible myocardial edema despite using hemofilter, and the 4th case had excessive oozing with an anticipated need for exploration. All the 4 cases were closed after 24-48 h. The ICU and hospital stay time were non-significant between both groups $(p=0.116$ and 0.183 , respectively). Arrhythmias were treated medically in all patients, and two patients in group A and one in group B required permanent pacemaker insertion. (Table 3). 
Table 1 Preoperative patients' data (continuous variables are presented as mean, standard deviation and range and categorical data as number and percent) (RVOT right ventricular outflow tract)

\begin{tabular}{llll}
\hline & $\begin{array}{c}\text { Group A } \\
(n=120)\end{array}$ & $\begin{array}{l}\text { Group B } \\
(n=100)\end{array}$ & p value \\
\hline $\begin{array}{l}\text { Age (months) } \\
\text { Range }\end{array}$ & $3.5-9$ & $8-14$ & $<0.001$ \\
Mean \pm SD & $7 \pm 3.1$ & $11 \pm 2.6$ & \\
Weight (kg) & & & $<0.001$ \\
Range & $4-8.5$ & $8.3-14$ & 0.455 \\
Mean \pm SD & $6.8 \pm 2.2$ & $9 \pm 3.1$ & $<0.001$ \\
Male & $66(55 \%)$ & $60(60 \%)$ & \\
McGoon ratio & $1.5 \pm 0.08$ & $1.61 \pm 0.07$ & \\
Mean \pm SD & & & \\
O2 saturation (\%) & & & \\
Range & $60-92$ & $76-88$ & \\
Mean \pm SD & $74 \pm 12$ & $82 \pm 4.3$ & \\
Pressure gradient across RVOT (mmHg) & & \\
Range & $67-90$ & $71-105$ & \\
Mean \pm SD & $81.6 \pm 6.3$ & $84.5 \pm 9.3$ & \\
\hline
\end{tabular}

Table 2 Operative data (continuous variables are presented as mean, standard deviation, and range and categorical data as number and percent) (RVOT right ventricular outflow tract, RV right ventricle, $P A$ pulmonary artery)

\begin{tabular}{|c|c|c|c|}
\hline & $\begin{array}{l}\text { Group A } \\
(n=120)\end{array}$ & $\begin{array}{l}\text { Group B } \\
(n=100)\end{array}$ & $p$ value \\
\hline \multicolumn{4}{|l|}{ Total operative time (minutes) } \\
\hline Range & $195-270$ & $210-315$ & $<0.001$ \\
\hline Mean \pm SD & $232 \pm 24.6$ & $277 \pm 21.3$ & \\
\hline \multicolumn{4}{|l|}{ Total bypass time (minutes) } \\
\hline Range & $52-110$ & $67-130$ & $<0.001$ \\
\hline Mean \pm SD & $60 \pm 11.2$ & $81 \pm 13.7$ & \\
\hline \multicolumn{4}{|l|}{ Ischemic time (minutes) } \\
\hline Range & $43-80$ & $47-95$ & $<0.001$ \\
\hline Mean \pm SD & $53 \pm 7.1$ & $64 \pm 12$ & \\
\hline \multicolumn{4}{|l|}{ Approach for RVOT resection } \\
\hline Trans-atrial- transpulmonary & $38(31.7 \%)$ & $40(40 \%)$ & \\
\hline Trans-ventricular & $82(68.3 \%)$ & $60(60 \%)$ & 0.198 \\
\hline Pulmonary valve commissurotomy & $48(40 \%)$ & $58(58 \%)$ & 0.008 \\
\hline Trans-annular patch & $72(60 \%)$ & $42(42 \%)$ & \\
\hline \multicolumn{4}{|l|}{ Post bypass pressure RV/PA } \\
\hline Range & $18-46$ & $24-44$ & 0.35 \\
\hline Mean \pm SD & $33 \pm 6.3$ & $34 \pm 9$ & \\
\hline
\end{tabular}

Table 3 Postoperative data.

\begin{tabular}{|c|c|c|c|}
\hline & Group A $(n=120)$ & Group B $(n=100)$ & $p$ value \\
\hline \multicolumn{4}{|l|}{ Time of ventilation (hours) } \\
\hline Range & $18-280$ & $14-248$ & 0.037 \\
\hline Mean \pm SD & $44 \pm 9.3$ & $41 \pm 11.5$ & \\
\hline \multicolumn{4}{|l|}{ ICU stay (days) } \\
\hline Range & $3-22$ & $3-23$ & 0.116 \\
\hline Mean \pm SD & $5.3 \pm 4.2$ & $6.3 \pm 5.2$ & \\
\hline \multicolumn{4}{|l|}{ Hospital stay (days) } \\
\hline Range & $7-28$ & $7-31$ & 0.183 \\
\hline Mean \pm SD & $10 \pm 4.8$ & $11 \pm 6.3$ & \\
\hline Exploration for bleeding & $4(3.3 \%)$ & $7(7 \%)$ & 0.233 \\
\hline Arrhythmia & $46(38.3 \%)$ & $36(36 \%)$ & 0.806 \\
\hline SVT & $22(18.3 \%)$ & $16(16 \%)$ & \\
\hline Nodal Rhythm & $21(17.5 \%)$ & $18(18 \%)$ & \\
\hline $\mathrm{CHB}$ & $3(2.5 \%)$ & $2(2 \%)$ & \\
\hline Deep Wound infection & $2(1.7 \%)$ & $6(6 \%)$ & 0.145 \\
\hline Diaphragmatic paralysis & $6(5 \%)$ & $3(3 \%)$ & 0.515 \\
\hline Operative mortality & $9(7.5 \%)$ & $6(6 \%)$ & 0.791 \\
\hline
\end{tabular}

\section{Pre-discharge echocardiographic data}

Pre-discharge echocardiographic data are presented in Table 4. Pericardial effusion was higher in group B but did not reach a significant value (11\% vs. $6.7 \%$; $p=0.336)$.

\section{Discussion}

The optimal surgical management of TOF has been the subject of ongoing debate, especially in the

Table 4 Pre-discharge echocardiographic data.

\begin{tabular}{|c|c|c|c|}
\hline & $\begin{array}{l}\text { Group A } \\
(n=120)\end{array}$ & Group B $(n=100)$ & $p$ value \\
\hline \multicolumn{4}{|l|}{ Pulmonary regurgitation } \\
\hline No-mild & $64(53.3 \%)$ & $50(50 \%)$ & \\
\hline Moderate & $43(35.8 \%)$ & $40(40 \%)$ & \\
\hline Severe & $13(10.8 \%)$ & $10(10 \%)$ & 0.835 \\
\hline \multicolumn{4}{|l|}{ PG across RVOT } \\
\hline Range & $15-40$ & $10-40$ & \\
\hline Mean \pm SD & $21 \pm 3.3$ & $22 \pm 5.2$ & 0.085 \\
\hline Residual VSD (<3 mm) & $7(5.8 \%)$ & $4(4 \%)$ & 0.758 \\
\hline $\begin{array}{l}\text { Pericardial effusion } \\
\text { Surgical evacuation } \\
\text { of PE }\end{array}$ & $8(6.7 \%) 0$ & $11(11 \%) 3(3 \%)$ & 0.3360 .092 \\
\hline
\end{tabular}

(Continuous variables are presented as mean, standard deviation, and range and categorical data as number and percent) (PE pericardial effusion, $P G$ pressure gradient, RVOT right ventricular outflow tract, VSD ventricular septal defect) 
developing countries with late presentation of TOF patients. Surgical management of TOF can be either with a total primary repair or staged repair. The superiority of one technique over the other is still debatable. Kanter and associates reported that primary repair or shunting of symptomatic neonates provides the same long-term outcome [5]. However, reports from other studies have shown superior results for primary total correction [4, 6-9].

The safety issue of CPB in small infants was argued. Hirsch and coworkers reported the rate of CPBrelated complications in neonates who underwent primary total correction versus those who underwent palliative procedures in different types of congenital cardiac pathology. They have shown that CPB per se is not an independent determinant of survival and concluded that effective repair and proper pre- and postoperative management are the critical determinants of survival [9]. Several recent studies supported the early total correction of TOF irrespective of age and weight $[1,2,4,7]$.

The age of our patients at primary intervention was relatively higher compared to other series, which could be attributed to late referral for surgery and crowded waiting lists. Furthermore, all patients had McGoon ratio between 1.2 and 1.6, which had put them in the category of less favorable anatomy and consequently less favorable outcome for many centers. Many authors have published a low mortality rate for primary repair even at a younger age; however, they have not considered pulmonary artery anatomy as a risk factor.

McGoon ratio was higher in group B, which could be attributed to the growth of the pulmonary arteries after performing MBT shunt. Although the rate of trans-annular patch use was higher in group A, we did not find a statistical difference between the two groups in post-repair RV/PA and RV/LV pressure gradients. The difference in total operative, cardiopulmonary bypass, and ischemic times was significantly different, and this was related to the nature of the reoperation in group B, which required a lot of dissection under bypass support. There was no significant difference in postoperative complications between the two groups. These results were the same as reported by many other authors who showed that a previous systemic-pulmonary artery shunting palliation was not a significant risk factor for mortality and there was no significant difference in the duration of ICU or hospital stay in the group of patients who had staged repair versus those who had primary repair $[2$, $3,5,10,11]$.

Our 30-day mortality was $7.5 \%$ in group A and 6\% in group B. In group A, two patients developed intractable pulmonary hemorrhage, five patients developed progressive low cardiac output and heart failure, and two patients died after prolonged ventilation with respiratory and multi-organ failure. The causes of death in group B were refractory ventricular arrhythmia in one patient, low cardiac output and heart failure in four patients, and sudden cardiac arrest in one patient. Mulder and associates have published a multi-institutional report that included 938 patients, and they found that mortality for repair versus shunt group was similar (4.3\% vs. $4.4 \%)$ [12].

In summary, this study showed that the outcome of primary TOF repair was comparable to that of staged repair. Operative times were prolonged with the staged repair; however, the primary repair was associated with longer ventilation time and more use of the transannular patch.

\section{Study limitations}

This study is a retrospective cohort study with its drawbacks of selection and referral biases. Another limitation is the short-term follow-up, and a longer follow-up study is recommended. Lastly, the study did not report the outcome of the shunt operations before offering a total repair in group $B$.

\section{Conclusion}

Primary repair of the tetralogy of Fallot in patients with borderline McGoon ratio is safe with low morbidity and mortality. It has the potential to decrease hospital stay, cost, and resource utilization compared to the two-stage repair.

\section{Abbreviations}

CHB: Complete heart block; CPB: Cardiopulmonary bypass; ICU: Intensive care unit; LV: Left ventricle; MBT: Modified Blalock-Taussig shunt; PA: Pulmonary artery; PG: Pressure gradient; RV: Right ventricle; RVOT: Right ventricular outflow tract; SVT: Supraventricular tachycardia; TOF: Tetralogy of Fallot; VSD: Ventricular septal defect

\section{Acknowledgements}

Not applicable.

Authors' contributions

BMA has made substantial contributions to the conception and design of the work, the acquisition, analysis, and interpretation of data, and the creation of new software used in the work, has drafted the work and substantively revised it, has approved the submitted version (and any substantially modified version that involves the author's contribution to the study), and has agreed both to be personally accountable for the author's own contributions and to ensure that questions related to the accuracy or integrity of any part of the work, even ones in which the author was not personally involved, are appropriately investigated, resolved, and the resolution documented in the literature. MAE, SB, and EEE have made substantial contributions to the conception, analysis, and interpretation of the data, substantively revised this work, has approved the submitted version (and any substantially modified version that involves the author's contribution to the study), and has agreed both to be personally accountable for the author's own contributions and to ensure that questions related to the accuracy or integrity of any part of the work, even ones in which the author was not personally involved, are appropriately investigated, 
resolved, and the resolution documented in the literature. All authors read and approved the final manuscript.

\section{Funding}

No external source of funding.

\section{Availability of data and materials}

Data are available on request.

\section{Ethics approval and consent to participate}

Ethics approval of the study protocol was approved by the Ethical Committee of the Faculty of Medicine at Benha and Tanta Universities and Atfal Misr Hospital. Committee's reference number is not applicable. The need for informed consent was waived due to the retrospective nature of the study.

\section{Consent for publication}

Not applicable.

\section{Competing interests}

The authors declare that they have no competing interests.

\section{Author details}

${ }^{1}$ Cardiothoracic Surgery Department, Faculty of Medicine, Benha University, 15 Hasan Muwafi St., Hi Elrawdah," New Benha, Qalyobia 13518, Egypt.

${ }^{2}$ Cardiology Department, Faculty of Medicine, Tanta University, Tanta, Egypt

${ }^{3}$ Cardiothoracic Surgery Department, Faculty of Medicine, Tanta University,

Tanta, Egypt.

Received: 22 November 2019 Accepted: 18 December 2019

Published online: 30 December 2019

\section{References}

1. Gerrah R, Turner ME, Gottlieb D, Quaegebeur JM, Bacha E (2015) Repair of tetralogy of Fallot in children less than 4 kg body weight. Pediatr Cardiol 36: 1344-1349

2. Mimic B, Brown KL, Oswal N, Simmonds J, Hsia TY, Tsang VT (2014) Neither age at repair nor previous palliation affects outcome in tetralogy of Fallot repair. Eur J Cardiothorac Surg 45:92-99

3. Fraser CD, McKenzie ED, Cooley DA (2001) Tetralogy of Fallot: surgical management individualized to the patient. Ann Thorac Surg 71 : 556-563

4. Menaissy Y, Omar E, Mofreh B, Alassal M (2019) Total correction of tetralogy of Fallot in the first 60 days of life in symptomatic infants: is it the gold standard? J Thorac Cardiovasc Surg 67(2). Georg Thieme Verlag KGDate: Feb 9, 2019 https://doi.org/10.1055/s-0039-1678698

5. Kanter KR, Kogon BE, Kirshbom PM, Carlock PR (2010) Symptomatic neonatal tetralogy of Fallot: repair or shunt? Ann Thorac Surg 89:858863

6. Pigula FA, Khalil PN, Mayer JE, Del Nido P, Jonas RA (1999) Repair of tetralogy of Fallot in neonates and young infants. Circulation 100: 157-161

7. Ramakrishnan KV, Zurakowski D, Pastor W, Jonas RA, Sinha P (2018) Symptomatic tetralogy of Fallot in young infants: primary repair or shunt-pediatric health information system database analysis. World $J$ Pediatr Congenital Heart Surg 9(5):539-554

8. Tamesberger MI, Lechner E, Mair R, Hofer A, Sames-Dolzer E, Tulzer G (2018) Early primary repair of tetralogy of Fallot in neonates and infants less than four months of age. Ann Thorac Surg 86:1928-1936

9. Hirsch JC, Mosca RS, Bove EL, EL. (2000) Complete repair of tetralogy of Fallot in the neonate results in the modern era. Ann Surg 232(4):508514

10. Seddio F, Migliazza L, Borghi A, Crupi G (2007) Previous palliation in patients with tetralogy of Fallot does not influence the outcome of later repair. J Cardiovasc Med 8:119-122

11. Arafat AA, Elatafy EE, Elshedoudy S, Zalat M, Abdallah N, Elmahrouk A (2018) Surgical strategies protecting against right ventricular dilatation following tetralogy of Fallot repair. J Cardiothorac Surg 13(1):14. Published 2018 Jan 22. https://doi.org/10.1186/s13019-018-0702-0
12. Mulder TJ, Pyles LA, Stolfi A, Pickoff AS, Moller JH (2002) A multicenter analysis of the choice of initial surgical procedure in tetralogy of Fallot. Pediatr Cardiol 23:580-586

\section{Publisher's Note}

Springer Nature remains neutral with regard to jurisdictional claims in published maps and institutional affiliations.

\section{Submit your manuscript to a SpringerOpen ${ }^{\circ}$ journal and benefit from:}

- Convenient online submission

- Rigorous peer review

- Open access: articles freely available online

- High visibility within the field

Retaining the copyright to your article

Submit your next manuscript at $\boldsymbol{\nabla}$ springeropen.com 